\title{
EM DEFESA DO ENSINO DE GRAMÁTICA NA ESCOLA
}

\author{
Marco Antonio Martins \\ Universidade Federal de Santa Catarina/CNPq
}

\section{RESUMO}

Assumindo os pressupostos da teoria da variação e mudança linguística e estudos sobre o ensino de gramática, apresentamos neste artigo resultados de uma pesquisa realizada no âmbito do Mestrado Profissional em Letras no Brasil/ProfLetras. A pesquisa diz respeito aos diferentes usos do acusativo anafórico de terceira pessoa em textos narrativos escritos por alunos do $9^{\circ}$ ano do ensino fundamental. Elabora-se uma proposta de ensino que considere o papel da escola na recuperação de formas não mais presentes na gramática do português brasileiro - tais como os clíticos acusativos de terceira pessoa $(\mathrm{o} / \mathrm{a})$. Sistematiza-se aqui uma proposta de tratamento didático-pedagógica para um ensino de gramática que considere a língua em uso.

PALAVRAS-CHAVE: Acusativo anafórico. Ensino de gramática. Variação.

\begin{abstract}
Assuming the assumptions of theory of variation and language change and studies about grammar teaching, we present, in this article, the results of a research done under the scope of the Professional Masters in Languages in Brazil/PROFLETRAS. The research refers to the different usages of the third person anaphoric accusative within narratives written by students who are in the ninth grade of elementary school. There is developed a proposal of teaching which takes into consideration the role of school in the recovery of forms no more existing within the grammar of spoken Brazilian Portuguese - as the accusative clitics of the third person $(\mathrm{o} / \mathrm{a})$. It is here systematized the proposal of didactic and pedagogical treatment for a grammar teaching based on the language usage.
\end{abstract}

KEYWORDS: Anaphoric Accusative. Grammar Teaching. Variation.

\section{INTRODUÇÃO}

O título deste artigo faz referência direta ao título de um artigo de Carlos Franchi ${ }^{1}$. Por isso as aspas. Penso que a discussão do autor sobre a temática, realizada na década de 1980, é bastante atual e com ele assumo que fundamental na descrição gramatical é

estudar a variedade dos recursos sintáticos expressivos, colocados à disposição do falante ou do escritor para a construção do sentido. Repetindo: gramática é o estudo das condições linguísticas da significação. É uma resposta sistemática e, quando possível, explícita, à questão fundamental a que já nos referimos neste texto e no início deste

\footnotetext{
* Professor do Departamento de Língua e Literatura Vernáculas da Universidade Federal de Santa Catarina e professor permanente do Programa de Pós-Graduação em Linguística da mesma instituição; bolsista de produtividade do PQ2 (processo 310728/2014-2) do CNPq; e-mail: marco.martins@ufsc.br.

${ }^{1}$ Este artigo foi publicado em um livro, com o mesmo nome, organizado por Sírio Possenti, com outros textos de Carlos Franchi (FRANCHI, NEGRÃO E MÜLLER, 2006).
} 
item: por que e como (e para quem e quando...) as expressões das línguas naturais significam tudo aquilo que significam! (FRANCHI, 2006, p.88 grifo meu).

Ainda nas palavras do autor,

Não é verdade que a gramática não tem a ver com a produção e a compreensão de textos: ela está na frasezinha mais simples que pronunciamos. Mas é preciso concebê-la de um modo diferente: como o conjunto de regras e princípios de construção e transformação das expressões de uma língua natural que as correlacionam com o seu sentido e possibilitam a interpretação. Antes de ser um livro de etiquetas sociais ou um manual descritivo, a gramática é, de início, esse saber linguístico que todo falante possui, em um elevado grau de domínio e perfeição. Em um segundo plano, a explicação formal do caráter abstrato e geral desse saber. (p. 99).

$\mathrm{Na}$ discussão sobre o tema nos muitos encontros sobre ensino de língua e de linguística no Brasil, temos nos deparado frequentemente com uma confusão quando o assunto é "ensino de gramática". Essa confusão em grande parte está correlacionada ao que se entende e se tem defendido/difundido/divulgado pelo rótulo "ensino de gramática". Precisamos acertar o passo e esclarecer que uma questão é o trato com o conhecimento linguístico que um indivíduo tem quando sabe/fala uma língua materna - ou seja, as regras de funcionamento - a gramática - dessa língua; e outra questão bastante diferente é o que o aluno precisará (ou não) aprender na escola sobre os diferentes usos ou normas dessa língua. Nesse contexto, o objetivo primeiro deste artigo é suscitar uma discussão que vise a esclarecer o que é gramática e, consequentemente, o que é "ensinar gramática".

O artigo está organizado em quatro seções: na primeira, apresento uma discussão a respeito dos muitos discursos sobre o que é "ensinar gramática" e a confusão que esses muitos discursos polarizados sobre a questão tem causado para quem tem de lidar diariamente com ensino de língua portuguesa nas salas de aula do ensino fundamental e médio; na segunda seção, apresento um estudo de caso com uma proposta de intervenção pedagógica desenvolvida no âmbito do mestrado profissional em Letras/PROFLETRAS no pólo de Natal/RN; na terceira seção, apresento resultados de uma pesquisa que revela o que as provas do ENEM tem cobrado em relação a conhecimentos gramaticais; e, por fim, na quarta e última seção apresento algumas considerações finais com uma agenda de trabalho para o ensino de língua portuguesa/de gramática.

\section{O que se entende (e se tem defendido) sobre "ensino de gramática" e os muitos discursos...}

Apesar da significativa contribuição de muitos estudos realizados no Brasil, desde algumas décadas atrás, no sentido de delinear orientações para práticas de ensino de língua portuguesa, ou, mas especificamente, de ensino de gramática (GÖRSKI; COELHO, 2006; 2009; VIEIRA; BRANDÃO, 2007; MARTINS; TAVARES, 2013; VIEIRA, 2013; MARTINS, 2013; MARTINS; VIEIRA; TAVARES, 2014), alguns discursos sobre o tema tem muito mais confundido do que ajudado na construção de um saber sobre o que significa "ensinar gramática na escola". A meu ver, esses discursos estão centrados em dois equívocos que precisam ser reparados: (1) o rótulo "ensino de gramática" tem sido usado, sem muita reflexão, para fazer referência ao ensino de uma norma padrão idealizada - e ensinar gramática contempla 
muitas outras atividades (VIEIRA, 2013, a sair); (2) imposições do tipo "isso não se deve ensinar na escola" tem, na minha opinião, deslocado o problema que a escola enfrenta em relação ao "o quê ensinar" quando o assunto é gramática; e isso desloca a questão ou para um ensino normativo da língua - de gramática como norma padrão - ou para o abandono completo do ensino da norma padrão assim como da própria gramática. Falar em ensino de gramática causa a alguns até certo constrangimento, tamanha é a confusão entre o que se entende por tal prática.

Em relação ao ponto em (1), sigo a proposta de Vieira (2013; a sair) e o trabalho que vem sendo realizado pelo grupo vinculado à disciplina "Gramática, Variação e Ensino" do Mestrado Profissional em Letras/PROFLETRAS no Brasil. Não vou me ater a essa discussão pelo que remeto o leitor aos textos publicados recentemente por Silvia Vieira (2013; a sair). No que se refere ao ponto em (2), gostaria de problematizar alguns discursos.

Em publicações recentes sobre a temática, encontramos citações como:

as práticas tradicionais de ensino de língua, sobretudo o chamado “ensino de gramática”, não têm mais razão de ser, se é que algum dia tiveram! Se nos detivermos apenas nas obras que trazem a palavra "gramática" em seu título, vamos encontrar, por exemplo, e citando apenas de memória: (BAGNO, 2013b)

Há uma confusão aqui quando se assume que "ensino de gramática" é "ensino de norma padrão"! A atividade de ensinar gramática vai muito além do ensino de normas da língua. Temos defendido que ensinar gramática envolve (1) o trabalho com o conhecimento epilinguístico que o aluno tem a respeito da língua que ele sabe/fala ao chegar na escola; (2) o trabalho com diferentes normas de uso (o que inclui a norma padrão - ou norma preditiva, nos termos de Faraco (2015) - mas não exclui todas as outras normas cultas e populares); e (3) o reconhecimento de que a relação entre a atividade epilinguística e o contínuo de normas da língua está a serviço da construção de textos orais e escritos. Vieira (a sair) tem defendido esses três aspectos do ensino de gramática como três eixos necessários a um ensino de língua portuguesa que busque efetivamente fazer sentido para que aprende e quem ensina.

Tenho dito que a escola ainda considera o aluno que chega aos bancos escolares como desprovido de conhecimento a respeito da língua materna por ele adquirida (e bastante consolidada quando esse aluno chega aos bancos escolares por volta dos sete anos de idade). Essa postura pode ser comparada a uma tentativa de ensinar a uma criança de sete anos a respirar quando ela já o faz (e muito bem e obrigado) quando chega à escola. Muitas vezes, as aulas de língua portuguesa/de gramática asfixiam os alunos como se eles já não soubesse português mesmo tendo aprendido tal língua como sua língua materna. É certo que a escola deve tornar explícitas (quando possível) os mecanismos linguísticos de significação - ou o por que, como para quem e quando as expressões linguísticas significam o que significam - assim como o pode fazer com o funcionamento da respiração. Mas, antes, deve partir do pressuposto básico de que os alunos já sabem/conhecem e utilizam os recursos linguísticos da língua (assim como já respiram) ou incorreremos no erro de sufocar nossos alunos ao dizer que eles não sabem português - ou não sabem respirar - apesar de já o fazerem com grande desenvoltura quando chegam aos sete anos na escola. É certo que a escola deve e tem por obrigação - além de tentar tornar transparente o conhecimento sobre a língua - ensinar técnicas de uso da língua - assim como diferentes técnicas de respiração (para manter a metáfora!) - e fazem com que o aluno domine diferentes normas da língua (inclusive a norma padrão) para produção de textos nos diferentes e mais variados contextos sócio-comunicativos.

Como bem coloca Marcos Bagno em sua Gramática de bolso do Português Brasileiro, publicada em 2013: 
A função da escola é ensinar o que as pessoas não sabem: ninguém precisa ensinar um brasileiro a dizer 'eu conheço ela muito bem', porque essa regra faz parte da gramática da nossa língua materna. Mas é preciso ensinar explicitamente a regra 'eu a conheço muito bem', porque ninguém aprende a falar assim em casa. (BAGNO, 2013, p. 37 - grifo meu)

Mais adiante, discutindo sobre a necessidade de um convívio entre diferentes normas no português brasileiro, esse autor assume que:

O reconhecimento da norma culta real não deve servir de base para um novo tipo de prescrição e repressão linguísticas. É preciso adotar a posição do convívio democrático e tranquilo entre as formas tradicionalmente padronizadas e as formas inovadores já incorporadas à atividade linguística dos falantes urbanos. Não vamos praticar uma prescrição às avessas: rejeitar as formas tradicionais para aceitar exclusivamente as inovadoras. $\mathrm{Na}$ prática linguística falada e escrita, existe lugar para todas elas. O importante é abandonar de vez a noção irracional de que as formas inovadoras constituem erros a ser evitados. É inútil tentar combater supostos 'erros' que já se fixaram nas variedades urbanas de prestígio, inclusive na nossa melhor produção literária desde o Romantismo" (BAGNO, 2013, p. 202 - grifo meu)

Concordo/concordamos na íntegra com o que aqui propõe o autor/"gramático": a escola deve ensinar o que as pessoas não sabem (e a norma padrão faz parte do "não conhecido"/ "dominado" pelos alunos antes de entrar na escola) e não podemos praticar uma "prescrição às avessas", impondo restrições ao ensino formal de língua portuguesa a ser praticado na e pela escola. No entanto, nos capítulos que seguem nessa mesma gramática de Bagno encontramos muitas seções com quadros indicadores sobre "o que não ensinar na escola". Nessas indicações são feitas afirmações categóricas de que o ensino de determinadas formas, construções e variantes (algumas obsoletas mesmo na variante falada culta do português brasileiro) deve ser abandonado pela escola. Vejamos alguns exemplos.

Sobre as conjugações verbais, há uma indicação explícita de que

Não tem cabimento ensinar a conjugação nas pessoas tu e vós: caso elas ocorram nos textos a serem lido em sala de aula, a professora pode explicar que tu é de uso restrito, que vós não se emprega há séculos em nenhum lugar onde se fala português no mundo. Além disso, é preciso deixar claro que você é a forma considerada "neutra", empregada de maneira não-marcada, ao passo que tu pode ser tomado, em algumas situações, como uma forma agressiva ou grosseira, por indicar excesso de intimidade. (BAGNO, 2013, p. 205 - grifo meu)

Ora, mesmo sabendo que a conjugação em vós não pertença à fala ou à escrita português culto brasileiro, porque perdemos um sistema de formas mais especificadas para a segunda pessoa do plural, tal sistema precisa ser recuperado e ensinado na escola. Justamente porque tais formas (nem de longe) não fazem mais parte do que é conhecido pelo aluno. Caso contrário, como o aluno poderá ler textos de sincronias passadas, por exemplo? Não só a conjugação em vós deve ser ensinada, como todo (ou quase) formas pronominais desse sistema perdido deve estar na agenda de um ensino formal na escola. É a escola o lugar em que tais formas podem/devem ser 
recuperadas! Claro que não faz o menor sentido cobrar que o aluno decore tal padrão idealizado e que o substitua pelo sistema de vocês - forma de segunda pessoa do plural no português culto falado e escrito no Brasil (ver Berlinck, Duarte e Oliveira, 2015). No entanto, abandonar a formalização de um ensino que recupere as formas de vós é negar ao aluno o acesso a bens culturais para os quais tal conhecimento certamente será requerido.

Em relação às conjugações em $t u$, a realidade é completamente diferente. O sistema de $t u$ é ainda muito utilizado em muitas comunidades de fala no vasto território brasileiro. Veja-se, por exemplo, o mapeamento apresentado em Sherre et al (2015) sobre a variação dos pronomes "tu" e "você" no Brasil. Nas palavras dos autores:

O pronome " $t u$ ", por sua vez, pode ser de uso extremamente natural, índice identitário da comunidade, em diversas localidades do grande território brasileiro, com possibilidade de concordância, em maior ou menor grau, a depender da formalidade da interação ou da escolaridade do falante. Isso se observa, por exemplo, no Rio Grande do Sul, em Santa Catarina, no Amazonas, no Pará e no Maranhão. (p. 215)

Em muitas localidades, essa, inclusive, é a única/ou a principal forma de expressão da segunda pessoa do singular. Como podemos não ensinar a conjugação de tu?

O ponto que quero destacar aqui, em relação à orientação de Bagno de que "Não tem cabimento ensinar a conjugação nas pessoas tu e vós" é que com esse discurso se instaura uma polarização que impõe o que se deve ou não ensinar na escola, tanto quanto o discurso polarizado a respeito de um ensino meramente da norma padrão da língua. E nesse discurso estabelece-se, portanto a alegada "prescrição às avessas", pelo autor condenada.

Sobre a famigerada questão da colocação pronominal no português brasileiro, assim promulga Bagno:

1. As diversas regras e sub-regras previstas pela tradição gramatical para a sintaxe dos clíticos devem ser abandonadas em favor da regra única que vigora no PB: o clítico vem sempre anteposto ao verbo principal.

2. Os demais usos previstos pela TGP (a falácia da ênclise como "regra geral" e a suposta obrigatoriedade da mesóclise), quando ocorrem em textos escritos autênticos lidos e trabalhados em sala, devem ser explicados pela professora, mas não como supostas formas mais 'corretas' de colocação de clíticos.

3. A perseguição purista à próclise absoluta, isto é, ao uso de clíticos em início de frase, deve ser denunciada e combatida como uma prescrição irracional que bate de frente com a intuição gramatical de todos os falantes do PB. É perfeitamente correto e legítimo iniciar frase com clíticos no PB, tal como ocorre em espanhol e italiano. (2013, p. 231-232 - grifo meu)

Quero destacar aqui que nos muitos estudos realizados sobre a sintaxe dos clíticos pronominais no português brasileiro falado e sobretudo escrito, considerando contínuos de uso que vão da modalidade da língua - fala e escrita - ao gênero textual, muitos e diferenciados são os padrões encontrados. Vejam-se, por exemplo, os trabalhos de Martins (2005), Vieira (2007). A ênclise ainda é bastante recorrente em alguns contextos, como em construções passivas ou com o pronome se indeterminador, por exemplo. 
Mais uma vez, esse discurso, polarizado de Bagno, sobre o que não se pode ensinar na escola instaura uma "prescrição às avessas" que não pode ter lugar nos bancos escolares que deve ter como norte o ensino de língua portuguesa como conhecimento epilinguístico, mas e sobretudo, pois a escola é o (único) lugar para isso, do ensino de diferentes normas da língua, que inclui necessariamente a norma padrão.

\section{Um estudo de caso: uma proposta de intervenção pedagógica desenvolvida no âmbito do PROFLETRAS/Natal (XAVIER, 2015)}

Considerando que precisamos articular um espaço de discussão sem polarizar o discurso no que se refere ao ensino de gramática nos ensinos fundamental e médio, um dos maiores desafios enfrentados pelo professor de português diz respeito, sem dúvida, a quais saberes gramaticais devem ser efetivamente acionados na escola. Muitas vezes, confunde-se ensino de português com ensino de uma norma padrão homogênea e abstrata, que em nada se aproxima dos diferentes usos da língua nas mais variadas situações de expressão sociocultural na multifacetada realidade sociolinguística brasileira. Diante do não saber o que (ou que norma, que gramática) ensinar - surgem dois grandes problemas, correlacionados entre si, que em muito têm prejudicado o ensino de português como língua materna: o preconceito linguístico e a falta de orientação em relação ao que é de fato "ensinar gramática" (MARTINS, VIEIRA E TAVARES, 2014).

As orientações oficiais propõem como alguns dos objetivos do ensino de língua portuguesa o reconhecimento e o respeito às variedades linguísticas, que permitam aos alunos utilizar a língua em diferentes modalidades e em diferentes registros, adequando-a às mais variadas situações de comunicação. Essas mesmas orientações, no entanto, ainda não se aplicam ao universo homogeneizador da língua escrita e ao que se tem chamado de língua ou norma padrão, relegando à variação e à diversidade - inerente a toda e qualquer norma linguística - o lugar do estereotipado e do socialmente marcado. Nesse quadro, perpetua-se o preconceito linguístico sob o mito de que existe uma única norma - a norma padrão - e de que essa deva ser o objeto das aulas de português como língua materna. Resulta daí uma cultura de substituição da variedade linguística do aluno, e não da desejável ampliação de seu repertório (MARTINS, VIEIRA E TAVARES, 2014).

Diante desse complexo quadro, justificam-se propostas de intervenção pedagógica que tomem por base muitas das descrições e análises dos diferentes usos no que respeita a aspectos do português brasileiro. Propostas cuja principal motivação, nesse sentido, seja sistematizar o tratamento didático-pedagógica de ensino de gramática que considere a língua em uso. É esse o desavio a que se propõem as pesquisas desenvolvidas no âmbito do mestrado profissional em Letras (PROFLETRAS) em curso no Brasil desde 2014. Retomarei a seguir uma pesquisa realizada na unidade do PROFLETRAS/Natal com ensino de gramática - com o acusativo anafórico - com alunos do ensino fundamental II na cidade do Natal/RN.

Xavier (2015) apresenta um diagnóstico da contribuição da escolarização para o ensino/aprendizagem da gramática do letrado, tendo em vista a escrita de alunos de uma turma do $9^{\circ}$ ano, último do ensino fundamental II, de uma escola pública da cidade do Natal/RN. A partir do diagnóstico, se propôs uma intervenção pedagógica para o ensino de diferentes formas de acusativo anafórico de $3^{\text {a }}$ pessoa em português.

O acusativo anafórico é o termo que preenche a posição de argumento interno de um verbo transitivo direto (verbo de dois argumentos) e, ao mesmo tempo, reitera no texto a referência de um elemento já apresentado anteriormente - ou seja o acusativo anafórico é antes um recurso gramatical a serviço da coesão textual. Muito descrito em estudos sociolinguísticos desenvolvidos no Brasil, considerando dados de fala e de escrita, o acusativo anafórico apresenta 
quatro possibilidades (variantes) diferentes: o pronome clítico, o pronome nominativo, o sintagma nominal e o objeto nulo, conforme exemplos a seguir retirados de Xavier:

(1) Mas a população descobre que se o [Vilarejo]i tivesse uma história, poderia salva-lo.

(2) Chamaram [Bia]i para escreve o livro de jave ele tâmbem foi cateiro fala coisa que não era mintira o povo descobriu e mandou chama ele.

(3) Antônio Biar escrevia [cartas falsas] i e entregava $\varnothing_{i}$

(4) Ai tiveram que chamar Bia para escrever [o livro]. Bia voutol e comecou a ouvir as pessoas para escrever, so que cada um contava uma bistoria diferente, um diz que quem fundou jávé foi indalecio, outra dizia que foi maria dina e assim ia... Bia já estava ficando loco de tanto uvir historias, certo dia os abtantes pediram para ver 0 livro, Bia mandou um menino entregar o livro, quando viram o livro, viram que bia não tinha escrito nada.

Duarte e Ramos (2015) apresentam um amplo mapeamento sociolinguístico dos usos dessas formas no português brasileiro. O que mais chama a atenção é que a forma mais utilizada mesmo na fala culta do brasileiro letrado é o objeto nulo e tal forma não é contemplada pelo ensino formal na escola nos anos de escolarização nos ensinos fundamental e médio. A questão que motivou a pesquisa de Xavier (2015) foi assentada nessa observação: depois de anos escolarização, em que o pronome oblíquo átono - forma clítica - deveria ser trabalhada - pois essa seria, por hipótese, a forma desconhecida pelo aluno já que é uma forma obsoleta mesmo na fala culta - quais a variantes utilizadas pelos alunos do final do último ano do ensino fundamental II?

Para a realização da pesquisa, Xavier propôs o seguinte esquema geral da sequência didática que foi aplicada na turma investigada:

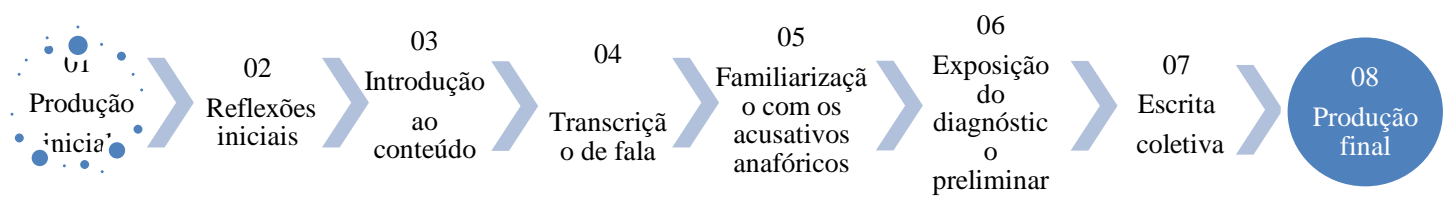

Figura 1: Sequência didática com propostas de atividades (Xavier, 2015, p. 84)

Observe-se a sequência didática envolveu uma atividade de produção textual inicial para que um diagnóstico fosse apresentado. Duas propostas de escritas foram realizadas com os alunos nesta primeira etapa: (i) um relato do filme "Narradores de Javé", previamente assistido e debatico com os alunos em sala; (ii) um relato de experiência pessoal no qual o aluno teria de relatar uma situação de risco pela qual ele ou alguém conhecido passou. A proposta pautada nesses dois gêneros levou em conta a proposta de Labov (2008 [1972]) de que o relato pessoal no qual se relata um risco de vida/ou de morte favoreceria o vernáculo e teria, por hipótese, menos formas da norma culta na escrita dos alunos.

Foram analisadas 32 narrativas escritas pelos alunos (16 relatos de filme e 16 relatos de experiência pessoal), e as distribuições das variantes em relação ao acusativo anafórico estão expressas nos gráficos 1 e 2 a seguir. 


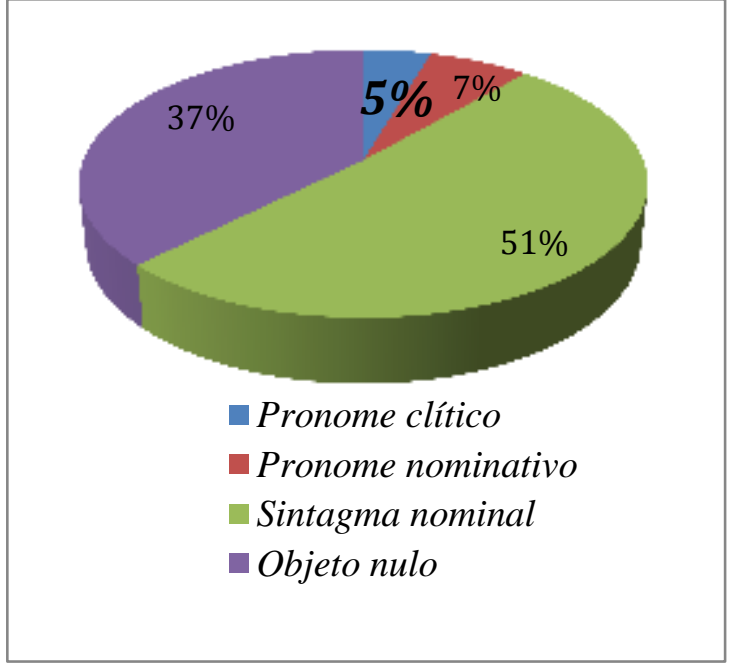

Grafico 1: Frequência do acusativo anafórico de $3^{a}$ pessoa em relatos do filme (Xavier, 2015, p. 66)

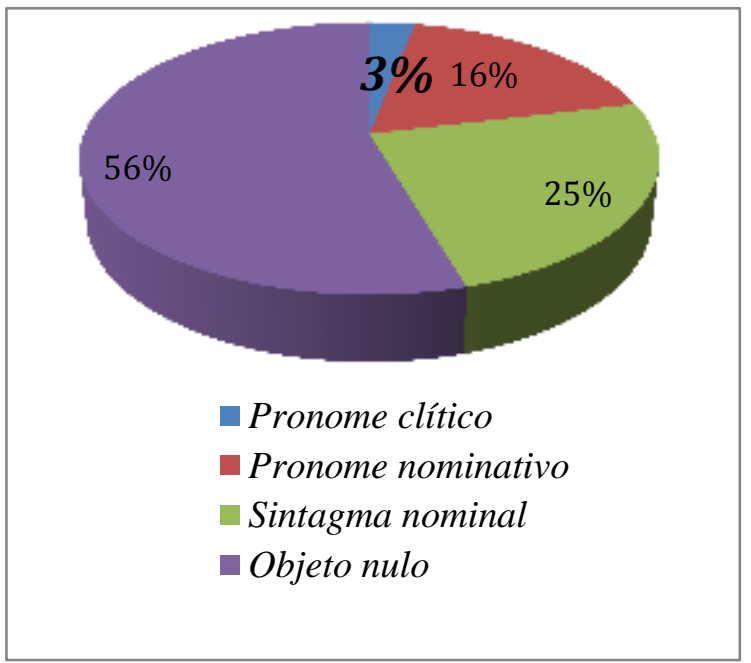

Gráfico 2: Frequência do acusativo anafórico de $3^{\text {a }}$ pessoa em relatos de experiência pessoal (Xavier, 2015, p. 76)

Em número brutos, nos relatos do filme foram encontradas 85 ocorrências de acusativo anafórico: 4 pronomes clíticos, 6 pronomes nominativos, 45 Sintagmas Nominais (SN) e 33 objetos nulos; nos relatos de experiência pessoal, 32 ocorrências: 1 pronome clítico, 5 pronomes nominativos, $8 \mathrm{SN}$ e 18 objetos nulos. Observe-se que as variantes mais utilizadas em ambas as narrativas escritas pelos alunos são o objeto nulo e o sintagma nominal, com uma pequena diferença/inversão entre o relato de filme $-51 \%$ de SN versus $37 \%$ de objeto nulo - e o relato de experiência pessoal $-25 \%$ de SN versus $56 \%$ de objeto nulo. Muito baixo foi o uso do pronome clítico, com apenas uma ocorrência no relato de experiência pessoal, conforme dado em (5).

(5) Num certo dia, ainda nesse ano a policia envadio a casa da [minha tia]i. Ela foi durmir na casa de outra tia minha, então en e meus pais e a filha da minha tia, íamos lá visita-la $a_{i}$ de madrugada.

Em relação à baixa frequência de pronomes nominativos, os resultados apresentados por Xavier (2015) corroboram o mapeamento feito por Duarte e Ramos (2015) que, ao contrário do que se tem afirmado, essa não é uma variante frequente na variedade falada no Brasil. Nas narrativas aqui analisadas, o pronome nominativo retomou sempre um constituinte próximo textualmente com traço [+animado] e apareceu em contexto de complemento de verbos no infinitivo em sentenças reduzidas de infinitivo, conforme exemplos em (6) a (9) a seguir.

(6) chamaram [Bia] i para escreve o livro de jave ele tâmbem foi cateiro fala coisa que não era mintira o povo descobriu e mandou chama ele.

(7) [antonio bia] i um mintirozo ai o povoado mandaro chamar ele $_{i}$

(8) E quando [Antônio biar] ${ }_{i}$ estava dormindo os povos foram acordar ele ${ }_{i}$

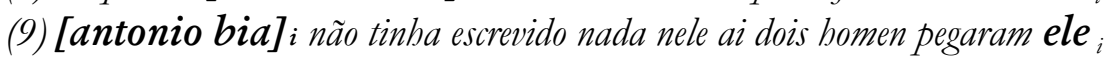

$\mathrm{Na}$ sequência da aplicação da proposta de intervenção foram realizadas com os alunos atividades reflexivas (como ilustram a sequência na figura 1) cujos objetivos foram os (i) de desenvolver na escrita desses alunos o conhecimento linguístico como atividade epilinguística no que diz respeito a aspectos gramaticais do acusativo e do acusativo anafórico em português; (ii) 
de trabalhar com diferentes normas do português, percorrendo diferentes gêneros textuais que contemplassem as diferentes variantes em questão e (iii) de compreender a função textual das variantes em questão na construção da significação geral do texto. É importante destacar que todas essas atividades envolvem o que se tem denominado por "ensino de gramática" 2 .

A última atividade foi a produção de uma narrativa ficcional pelos alunos. Nos resultados gerais, considerando a escrita dos mesmos alunos depois de aplicadas as sete etapas da sequência didática (cf. figura 1) foram encontrados nas narrativas ficcionais, em números brutos, 100 ocorrências de acusativo anafórico: 45 pronomes clíticos, 3 pronomes nominativos, 42 SN e 10 objetos nulos, cujos percentuais estão dispostos no gráfico 3 a seguir.

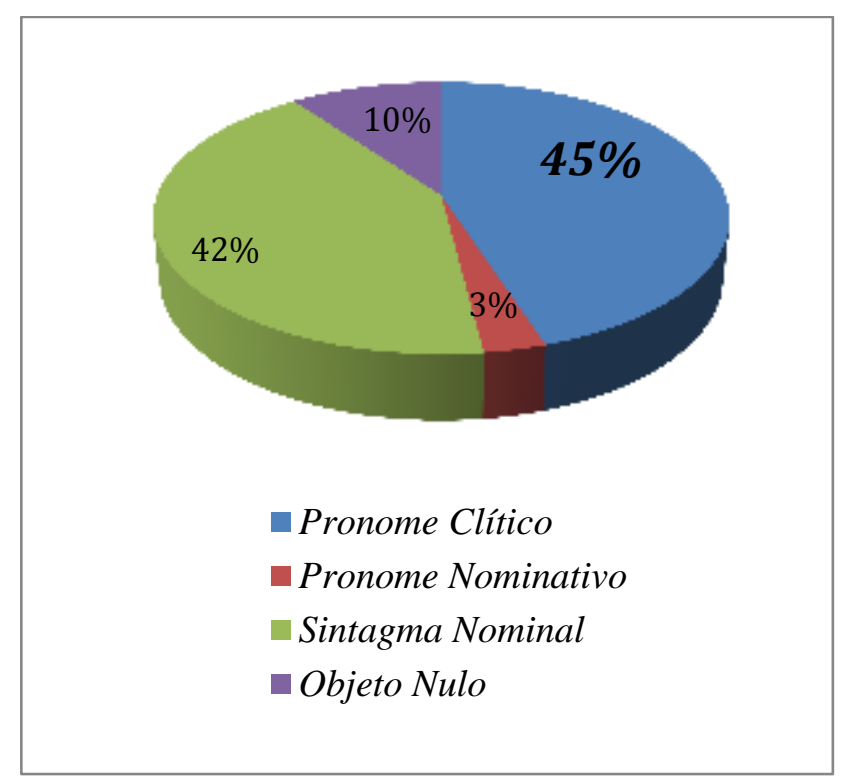

Gráfico 3: Frequência do acusativo anafórico de $3^{a}$ pessoa em narrativa ficcional - escrita final dos alunos (Xavier, 2015, p. 115)

Atestou-se um aumento considerável na frequência de uso de 3\% e 5\% nas primeiros textos, antes da aplicação da sequência didática, nos relatos do filme e nos relatos de experiência pessoal respectivamente, para $45 \%$ nas narrativas ficcionais, escritas depois da aplicação da sequência didática. É importante considerar que a escrita final foi logo após o trabalho muito de perto com o acusativo anafórico com os alunos e as diferentes possibilidades de realização do acusativo anafórico, o que pode ter elevado sobremaneira o uso do pronome clítico. Mas o fato é que com a aplicação da sequência, se discutiu gramática - conhecimento epilinguístico - e outras possibilidades/formas de retomada anafórica - para além do objeto nulo já conhecido e utilizado pelos alunos - foi usada. E repito: tudo isso envolve "ensinar gramática"!

\section{E por onde anda "a gramática que deveria estar aqui?" Breves palavras a respeito de uma análise das provas do ENEM (COSTA DA SILVA; CARVALHO JR., 2016)}

Nos muitos discursos polarizados sobre ensino de gramática entre o que a escola deve e o que a escola não deve ensinar, não podemos deixar de observar que, para retomar as palavras de

\footnotetext{
${ }^{2}$ As atividades e o relato da aplicação dessas atividades estão descritas com detalhes em Xavier (2015), pelo que remeto leitor interessado ao texto, disponível no banco de dissertações do PROFLETRAS da CAPES.
} 
Foltran (2013, p. 104), "frente aos mais diferentes desdobramentos provocados por essa discussão, acho que podemos afirmar que 'jogaram fora a criança junto com a água do banho"'. Ou seja, na tensão entre orientações extremistas em relação ao ensino de gramática - com os mais puristas ainda confundindo ensino de gramática com ensino de norma padrão e os nada conservadores que orientam para o abandono por completo de um ensino formal da norma padrão (ou de variantes em desuso no português brasileiro culto) - os professores de língua portuguesa se encontram perdidos em relação ao o que realmente é ensinar gramática. Temos/tenho advogado uma posição "mais equilibrada" na qual o ensino de gramática envolve atividades de reflexão linguística, como conhecimento epilinguístico e metalinguístico, de conscientização do contínuo de normas que envolvem os mais diferentes usos linguísticos contemplando também, e inclusive, o ensino de norma padrão - e da interação entre conhecimento gramatical e a construção do sentido nos mais variados textos orais e escritos a serem produzidos na escola e fora dela. Vieira (a sair) tem denominado esses três domínios de eixos que devem orientar as aulas de língua portuguesa e a formação dos nossos professores nos cursos de letras e nos programas de Pós-Graduação cujo foco é a formação docente, como é o caso do mestrado profissional PROFLETRAS.

Nesse contexto, não podemos negar que o ensino de gramática deve instrumentalizar os alunos para o trabalho reflexivo com a língua. Também não podemos negar "que um ensino de gramática que privilegia mera etiquetação de termos não tem uma funcionalidade em direção a nenhuma competência e, muito menos, aos objetivos pretendidos", como muito bem refere Foltran (2013, p. 104). Por esse motivo, precisamos acertar o passo e buscar um ensino de gramática que contemple diferentes atividades de reflexão e reconhecimento de normas para que, ao explorar diferentes recursos linguísticos expressivos, nossos alunos possam produzir textos coesos e coerentes e a gramática esteja, nesse sentido, a serviço da significação dos textos a serem produzidos nos mais variados contextos sócio-comunicativos.

As provas do Exame Nacional de Ensino Médio (ENEM) podem ser tomadas como um termômetro da afirmação de Foltran (2013) quando diz que a junto com a água do banho a criança foi jogada fora; ou seja, de que na tensão entre o que ensinar e o que não ensinar em relação à gramática, não se ensina nada. Costa da Silva e Carvalho Jr. (2016) apresentam um diagnóstico dos conteúdos de Língua Portuguesa contemplados nas provas do ENEM, no período de 1998 a 2015. Buscando observar de que maneira nas provas se desvela uma cobrança de conhecimentos de gramática, propriamente ditos, esses autores analisaram questão a questão em busca de um diagnóstico de como os conhecimentos gramaticais e seus mecanismos linguísticos de significação e suas nomenclaturas são cobrados nas provas. Para isso, agruparam as questões em quatro grandes grupos, assim especificados pelos autores:

Grupo 1 - Mecanismos linguísticos-gramaticais (fonética-fonologia, morfologia, sintaxe, pontuação, acentuação gráfica, ortografia e semântica)

Grupo 2 - Textos e seus contextos (Tipologia e Gênero textuais, Interpretação e compreensão textual, correlação textual, função e figura de linguagem, estratégias e intenções comunicativas e hipertexto).

Grupo 3 - A arte como saber cultural e estético e as TIC (linguagem corporal, literatura, teatro, funções da arte, diversidade artística, dança, tecnologias da comunicação e da informação). 
Grupo 4 - A língua portuguesa como língua materna. (variedades linguísticas: normas, registros, variação diatópica e diastrática). (COSTA DA SILVA; CARVALHO Jr., 2016, p. 13)

Nesse agrupamento das questões nos quatro grandes grupos, Costa da Silva e Carvalho Jr. levaram em conta o conteúdo e/ou assunto identificado no enunciado e na elaboração - i.e. nas alternativas elencadas - das questões provas em questão. O objetivo primeiro foi mapear o que está sendo cobrado em relação ao conhecimento do conjunto de regras sobre "as condições linguísticas de significação" ou sobre "por que e como (para quem e quando...) as expressões das línguas significam tudo aquilo que significam!", para retomar (mais uma vez e sempre!) as palavras de Carlos Franchi (2006, p. 88), conforme citação no início deste texto. Um exemplo de questões dessa natureza pode ser observada abaixo em que na prova se aciona o conhecimento epilinguístico do pronome SE em português, se recíproco ou se reflexivo, na tirinha da Mafalda de Quino.

08

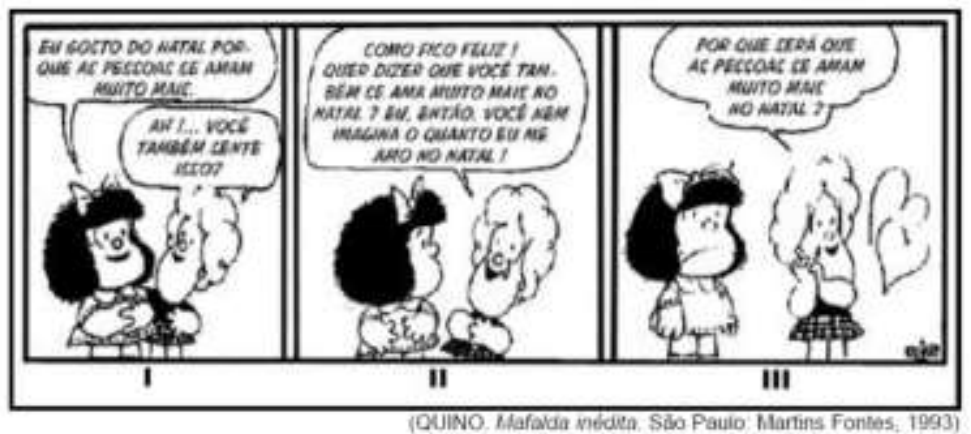

Observando as falas das personagens, analise o emprego do pronome SE e o sentido que adquire no contexto. No contexto da narrativa, e correto afirmar que o pronome SE.

(A) em $\mathrm{L}$, indica reflexividade e equivale a "a si mesmas".

(B) em Il, indica reciprocidade e equivale a "a si mesma".

(C) em III, indica reciprocidade e equivale a umas às outras".

(D) em I e III, indica reciprocidade e equivale a "umas as outras"

(E) em ll e III, indica reflexividade e equivale a "a si mesma "e "a si mesmas", respectivamente.

Figura 1: ENEM - Prova 1999 - Questão 08

(COSTA DA SILVA; CARVALHO Jr., 2016, p. 14)

Os resultados gerais dos quadro grupos de questões, em percentuais, estão sistematizados no gráfico 4 a seguir. 


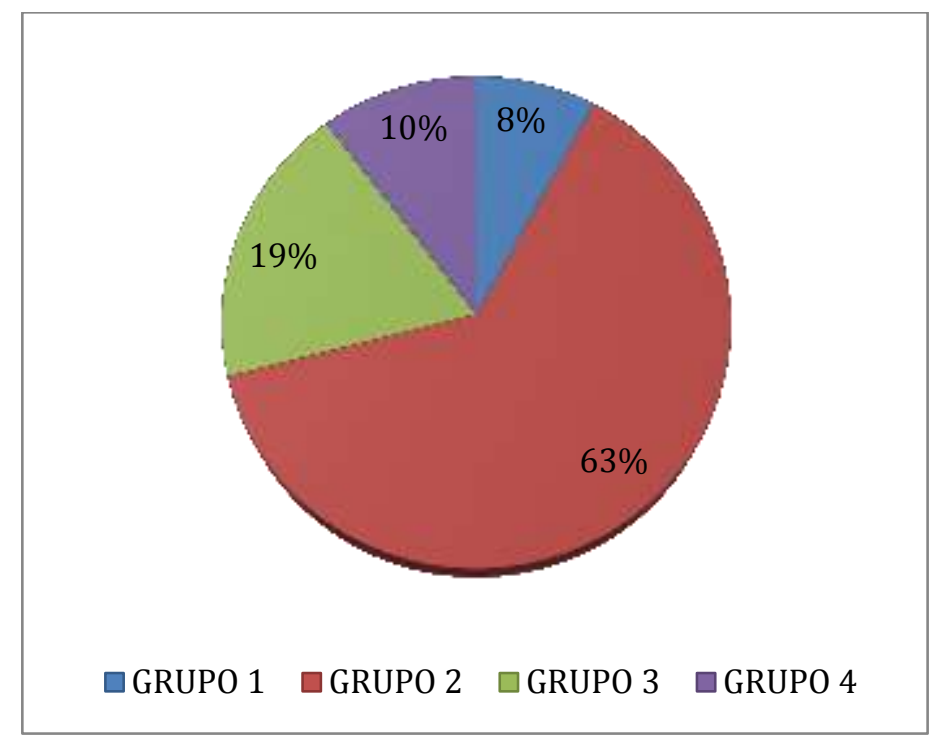

Gráfico 4: Frequência dos grupos de questões nas provas do ENEM de 1998 a 2015 (COSTA DA SILVA; CARVALHO Jr., 2016, p. 17)

Como se pode observar, é flagrante que questões do grupo 1 que se voltam ao conhecimento de mecanismos linguísticos gramaticais - nos diferentes níveis de análise linguística (fonéticafonologia, morfologia, sintaxe, pontuação, acentuação gráfica, ortografia e semântica) perfazem um total muito baixo - apenas 8\% - das questões das provas do ENEM no período de 1998 a 2015. Mais da metade das questões das provas, $63 \%$, estão centradas em conhecimentos textuais (Tipologia e Gênero textuais, Interpretação e compreensão textual, correlação textual, função e figura de linguagem, estratégias e intenções comunicativas e hipertexto). $O$ grande questionamento que se abre é com os esses resultados é: se a gramática "tem a ver com a produção e a compreensão de textos", como muito bem defende Franchi (2006), como nossos alunos estão produzindo e compreendendo textos sem o ensino formal de gramática? Pois se tomarmos as provas do ENEM como um "termômetro" do que é efetivamente ensinado/cobrado nos ensinos fundamental e médio, o quadro que se apresenta é o de que a gramática foi mesmo reduzida - quando aparece no ensino formal - a um percentual que a coloca às vésperas do completo abandono; ou seja, água e criança foram jogadas fora!

Se consideramos que os documentos oficiais preveem que

as situações didáticas devem, principalmente nos primeiros ciclos, centrar-se na atividade epilinguística, na reflexão sobre a língua em situações de produção e interpretação, como caminho para tomar consciência e aprimorar o controle sobre a própria produção linguística. $\mathrm{E}$, a partir daí, introduzir progressivamente os elementos para uma análise de natureza metalinguística. O lugar natural, na sala de aula, para esse tipo de prática parece ser a reflexão compartilhada sobre textos reais. (PCN, 1997, p. 31)

o que podemos depreender com a análise de Costa da Silva e Carvalho Jr. é que não é isso o que análise das questões do ENEM deixam evidente! O conhecimento epilinguístico tem sido muito pouco cobrado e consequentemente pouco ensinado.

\section{CONCLUSÕES: UMA AGENDA DE TRABALHO PARA O ENSINO DE LÍNGUA PORTUGUESA/DE GRAMÁTICA}


Nos moldes da proposta de intervenção pedagógica aplicada em uma turma do $9^{\circ}$ ano do ensino fundamental II, desenvolvida no âmbito de uma pesquisa no mestrado profissional em Letras/PROFLETRAS e aqui apresentada, necessário se faz assumir uma abordagem equilibrada em relação aos muitos discursos sobre ensino de gramática nas escolas. Nessa abordagem, é imprescindível (1) o trabalho com o conhecimento epilinguístico que o aluno tem a respeito da língua que ele sabe/fala ao chegar na escola (um ensino de gramática criativo, cf. Pires de Oliveira, 2013); (2) o trabalho com diferentes normas de uso (o que inclui a norma - não em uso, pois é abstrata e idealizada - padrão, mas não exclui todas as demais normas cultas e populares); e (3) a articulação entre o conhecimento epilinguístico e as diferentes normas de uso da língua a serviço da construção e compreensão de texto orais e escritos nos mais variados contextos sóciodiscursivos. E repito: tudo isso envolve “ensino de gramática"!!! O reconhecimento e o trabalho nos três eixos, para retomar Vieira (a sair), tem de ser um norte nessa empreitada em busca do elo perdido nos muitos discursos.

Então, considerando que precisamos (i) conhecer as práticas escolares presentes nas escolas assim como os materiais didáticos por elas adotados para que se possa investir na elaboração de propostas didático-pedagógicas, que configurem práticas sociolinguisticamente fundamentadas; (ii) averiguar o papel da escola no ensino/na recuperação, no curso dos diferentes anos de escolarização, de formas obsoletas na gramática do português culto falado e escrito no Brasil; e (iii) fomentar uma discussão sobre o papel da escola no que se refere ao ensino de gramática e ao ensino de diferentes normas do português, surgem dois grandes problemas que em muito têm prejudicado uma definição para o que se deve entender por "ensino de gramática": (1) a associação do ensino de gramática a somente ao ensino de norma padrão e (2) um discurso polarizado (de uma lado proferido pelos puristas da língua e de outro pelos avessos ao ensino da norma padrão) que busque orientar o que deve ou não ser ensinado na escola!

Em busca de uma posição equilibrada quando o assunto é "ensinar gramática", concordamos com Martins, Vieira e Tavares (2014) quando afirmam que

é preciso não só ampliar a descrição das variedades cultas e populares, nas modalidades falada e escrita e nos mais diversos registros, na extensa área territorial brasileira, mas também divulgar didaticamente os resultados dessas descrições para a comunidade de alunos e professores de Português [...]. (p. 34)

Destaque-se que muitos estudos que apresentam um grande esforço em oferecer material dessa natureza ao público interessado pelo ensino de Língua Portuguesa já foi produzido e publicado (GÖRSKI; COELHO, 2006; 2009; VIEIRA; BRANDÃO, 2007; MARTINS; TAVARES, 2013; VIEIRA, 2013; MARTINS, 2013; MARTINS; VIEIRA; TAVARES, 2014).

Concordamos igualmente com Foltran (2013) quando afirma que

se tivermos em mente que ao fazermos a análise sintática de uma sentença estamos explicando por que aquela sentença significa o que ela significa, o ensino de gramática vai muito além do ensino de norma. Aliás, o ensino de gramática deve ser, uma vez por todas, desvinculado do ensino de norma. Ensinar gramática é operar com os conhecimentos que o falante tem de sua própria língua e torná-los explícitos. É levar à percepção de que, apesar de termos um número infinito de possibilidades de sentenças na língua, temos um número bastante reduzido de estruturas linguísticas. Levar ao conhecimento e descrição 
dessas estruturas é um trabalho instigante, além de ser um momento privilegiado para o desenvolvimento do pensamento científico. (p. 214)

E para finalizar retomo Franchi (2006), reafirmando que defendo neste texto que para "o que é mesmo ensinar gramática"

Interessa pouco descobrir a melhor definição de substantivo ou de sujeito ou do que quer que seja. No plano em se dá a análise escolar, certamente não existem as boas definições. Seria mais fácil fazê-lo em uma teoria formal do que em uma análise que tateie somente pela superfície das expressões. Mas interessa, e muito, levar os alunos a operar sobre a linguagem, rever e transformar seus textos, perceber nesse trabalho a riqueza das formas linguísticas disponíveis para suas mais diversas opções.

[...] com isso, parece-me, reintroduz-se na gramática o seu aspecto criativo: o que permite ao falante compreender, um primeiro passo, os processos diferenciados de construção das expressões para, depois, um dia, e se for o caso, construir um sistema nocional que lhe permita descrever esses processos, falar deles, em uma teoria gramatical." (FRANCHI, 2006, p. 63-64).

\section{REFERÊNCIAS BIBLIOGRÁFICAS}

BAGNO, M.. Gramática de bolso do português brasileiro. São Paulo: Parábola Editorial, 2013a.

. Ensino de português: por que nada mudou em 30 anos? 2013b. Disponível em < http://e-proinfo.mec.gov.br/eproinfo/blog/preconceito/ensino-de-portugues-por-que-nadamudou-em-30-anos.html> acesso em 15 de fevereiro de 2016.

Gramática Pedagógica do Português Brasileiro. São Paulo: Parábola Editorial, 2011.

BERLINCK, R. A.; DUARTE, M. E. L.; OLIVEIRA, M. Predicação. In: Mary A. Kato; Milton do Nascimento (Org.). A Construção da Sentença; Gramática do Português Culto Falado no Brasil. 1a. ed. São Paulo: Contexto, 2015, v. II, p. 81-150.

BRASIL. Parâmetros Curriculares Nacionais (PCNs). Língua Portuguesa. Ensino Fundamental. Terceiro e quarto ciclos. Brasília: MEC/SEF, 1998.

COSTA DA SILVA, F.; CARVALHO Jr. S. V. Cadê a gramática que deveria estar aqui? Análise gramatical das provas do ENEM. Monografia de especialização. Especialização em Ensino de Português e Linguística. Natal, 2016.

DUARTE, M. E. L.; RAMOS, J. M. Variação nas funções acusativa, dativa e reflexiva. In: MARTINS, M. A. ABRAÇADO, J. Mapeamento Sociolinguístico do Português Brasileiro. São Paulo: Contexto, 2015, p. 173-195.

FARACO, C. A. Norma culta brasileira: construção e ensino.. In: Ana Maria S. Zilles; Carlos Alberto Faraco. (Org.). Pedagogia da variação linguística: língua, diversidade e ensino. 1ed.São Paulo: Parábola Editorial, 2015, p. 19-30.

FOLTRAN. Maria José. Ensino de sintaxe: atando as pontas. In: MARTINS, M. A. (org.) 
Gramática e ensino.1ed. Natal: EDUFRN, 2013, p. 167- 185.

FRANCHI, C.; NEGRÃO, E.; MÜLLER, A. L. Mas o que é mesmo gramática? São Paulo: Parábola, 2006.

GORSKI, E. M.; COELHO, I. L. Variação linguística e ensino de gramática. Working papers em Linguistica, 10 (1): Florianópolis, 2009, p. 73-91.

LABOV. W. Padrões sociolinguísticos. Trad. Marcos Bagno, Maria Marta Pereira Scherre, Caroline Rodrigues Cardoso. São Paulo: Parábola Editorial, 2008.

MARTINS, M. A. (Org.) Gramática e ensino. Natal: EDUFRN, 2013.

MARTINS, M. A. Entre Estrutura, Variação e Mudança: uma análise sincrônica das construções com SE indeterminador no Português do Brasil. Dissertação de Mestrado. Programa de PósGraduação em Linguística. Florianópolis, 2005.

MARTINS, M. A.; TAVARES, M. A. (Orgs.) Contribuições da sociolinguística e da linguística retórica para o ensino de lingua portuguesa. Natal, RN: EDUFRN, 2013.

MARTINS, M. A.; VIEIRA, S. R.; TAVARES, M. A. (Orgs.) Ensino de português e sociolinguística. São Paulo: Contexto, 2014.

PIRES DE OLIVERIA, R. A gramática do sentido na escola. In: Marco Antonio Martins. (Org.). Gramática e Ensino. 1ed.Natal: Editora da Universidade Federal de Natal, 2013, v. 1, p. 229-260. SCHERRE, M. M. P.; DIAS, E. P.; ANDRADE, C. Q.; MARTINS, G. F. Variação dos pronomes. In: MARTINS, Marco Antonio; ABRAÇADO, Jussara. (Org.). Mapeamento sociolinguístico do português brasileiro. 1ed.São Paulo: Contexto, 2015, v. , p. 133-172.

VIEIRA, S. R.; BRANDÃO, S. F.(Orgs.) Ensino de gramática: descrição e uso. São Paulo: Contexto, 2011.

VIEIRA, S. R. Três eixos para o ensino de gramática: uma proposta experimental. Ms.

Sociolinguística e ensino de português: para uma pedagogia da variação linguística. In:

MARTINS, M. A.; TAVARES, M. A. (Orgs.) Contribuições da sociolinguística e da linguística retórica para o ensino de língua portuguesa. Natal, RN: EDUFRN, 2013, p. 53 - 90.

Colocação pronominal. In: VIEIRA, S. R; BRANDÃO, S. F.. (Org.). Ensino de gramática: descrição e uso. 2ed.São Paulo: Contexto, 2011, v. 1, p. 121-146.

XAVIER, A. C. O acusativo anafórico e normas do português na escola: uma proposta de intervenção para o ensino de gramática. Dissertação de Mestrado. Mestrado Profissional em Letras. Natal, 2015

Recebido em 15/02/2017

Aceito em 20/04/2017

Publicado em 25/05/2017 